\title{
To Study the Nature of Geopathic Stress Caused by Ground Water using NaaV Meter and Proton Magnetometer
}

\author{
Aishwarya Bhimraj Gawand ${ }^{1}$, Dr. S.B.Gaikwad ${ }^{2}$ \\ 'JSPM's Jayawantrao Sawant College of Engineering, Pune, Maharashtra, India. \\ ${ }^{2}$ New Arts Commerce \& Science College, Ahmednagar, Maharashtra, India. \\ *Corresponding Author: Aishwarya Bhimraj Gawand, JSPM's Jayawantrao Sawant College of \\ Engineering, Pune, Maharashtra, India.
}

\begin{abstract}
The energy emitted by the earth at a specific location which affects the normal human body function is termed as geopathic stress (GS). Scientific studies of the exact nature and characteristic of geopathic stress are sparse and yet to receive appropriate attention. Some studies indicate that geopathic stress may be of electromagnetic nature. This paper attempts to make use of 'Naav meter and Proton Magnetometer' to study the nature of geopathic stress. The results indicate that this stress is in the form of Elctro magnetic waves.
\end{abstract}

Keywords: Geopathic Stress, Naav meter, Proton Magnetometer, Electromagnetic waves.

\section{INTRODUCTION}

Geopathic stress is a distorted or disrupted electromagnetic field of the Earth. Underground streams, sewers, water pipes, electricity, tunnels and underground railways, mineral formations and geological faults distort the natural resonance of the Earth thus creating geopathic stress (GS). Sleeping or spending a lot of time in geopathic stress zones can ill effects on our health, performance and wellbeing.

Dowsers and geobiologists have termed location of ground water as "water veins" or "earthrays". In recent years, it is expressed as geopathic stress (GS). The nature of geopathic stress is very complex due to many reasons, such as unclearness of the mechanism lying on the basis of their origin. The major causes of natural origin of GS are associated with the subterranean water flows at various depths with active geological faults. Extensive work has been published by various researchers to understand the nature and effect of GS on the built environment. Literature survey reveals that GS may be a form of imbalanced electromagnetic energy spectrum or subtle energy. However, a systematic scientific device is required to study the nature of geopathic stress. An attempt is made to study the nature of Geopathic Stress caused by ground water using NaVV meter and Proton magnetometer.

\section{EXPERIMENTAL DETAILS}

\section{NAAV METER:}

An attempt is made to study the interaction of Laser light beam with Geopathic Stress using NaaV meter. In present device there is a gap between laser light source and detector. In case Geopathic Stress is present in the gap, then interaction occurs between photons of laser light and Geopathic Stress which changes the current. If Geopathic Stress is not present in the gap of source and detector, then no interaction occurs keeping the current constant.

\section{PROTON MAGNETOMETER}

The orbiting electron acts just like electric current in a coil of wire and sets up a magnetic field about the atom. The proton, the main mass of the atom, is also in motion, spinning about its centre, so that the

whole atom looks like a magnetic gyroscope, whose magnetic poles are on its spin axis. Gyroscopes have idiosyncrasies revealed to mechanical engineers, one of them being that they will process if 
acted upon by an external field. In the hydrogen proton's case, its spin axis will wobble or process about the direction of the earth's magnetic field if that is the only magnetic field acting on it. The frequency of precession will be proportional to the strength of the field and is given by

$\mathrm{v}=\mathrm{kB}$

where $\mathrm{v}=$ frequency of precession

$\mathrm{k}=4.26 \mathrm{x} 103 \mathrm{~Hz} /$ weber for hydrogen

$\mathrm{B}=$ intensity of magnetic field.

A NaaV meter is placed at the predetected stress zone. The selenium photodiode and laser light source are arranged as shown in figure 1. The box is enclosed such that no external light would enter the box. Using copper L rods, the geopathic stress zones on the Mumbai-Pune expressway and residential area were located. The current was measured inside and outside the GS. The geopathic stress moves vertically upwards and laser light beam travels in horizontal direction. Both are mutually perpendicular. But at same time the laser light beam is also parallel to source of geopathic stress (underground water vein). Therefore an attempt is also made to measure variation of current by rotating the horizontally moving light beam from 00 to3600 with respect to vertically moving geopathic stress. This exercise has been carried out for the first time to confirm whether the GS get distributed in all possible directions above the earth surface. The study of the relationship between current and angle has been carried out; the graphs of which are shown in figure 4 and figure 5 .

The instrument used for this study consists of a sensor and a detector. The sensor is mounted by means of a rod is kept $1 / 2$ metre above the ground. The detector is connected to the sensor by means of a $2 \mathrm{~m}$ long two core shielded cable. Sensor was arranged with a arrow mark and is pointed towards north.one detector has a manual button anal it is used to take the measurements.

The sensor consists of a normal sample of hydrogen - rich material called as a polarizing liquid. The protons present in the liquid are randomly oriented and behave like a magnetic dipole. When it is Placed in an external magnetic field, a torque is exerted on it, which aligns its magnetic movement and causes a precession about the spin axis.

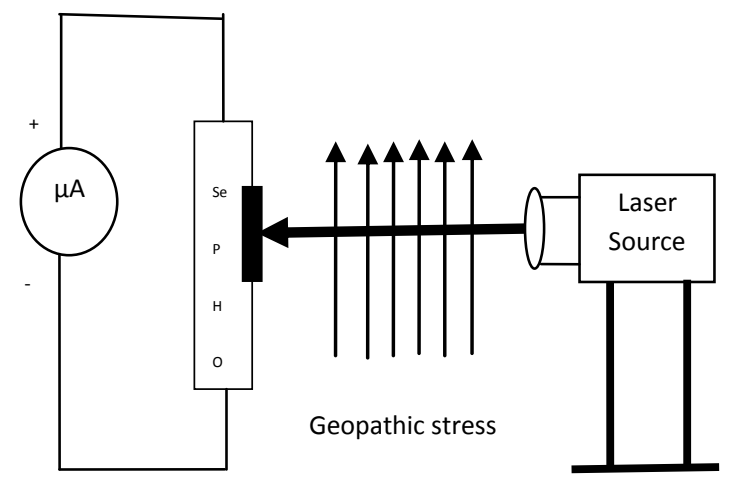

Fig 1. Experimental setup (NaaV meter)

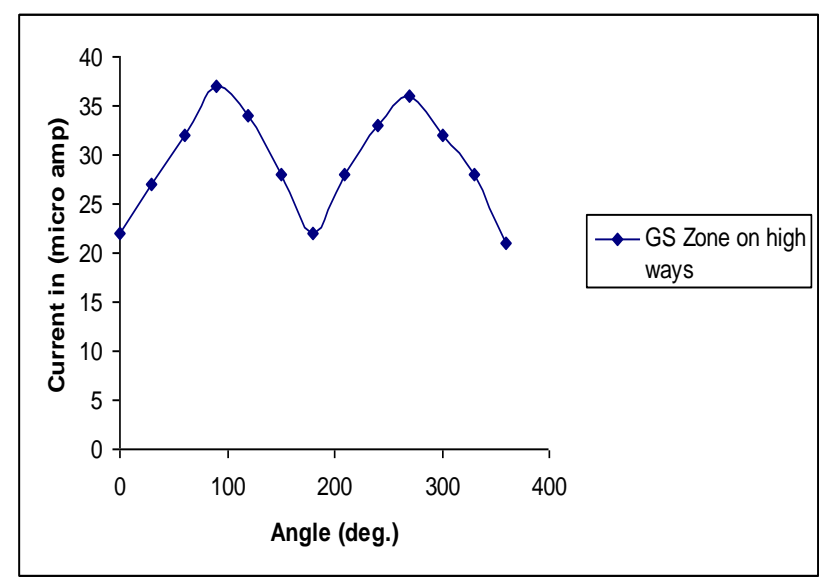

Fig 2. Graph for variation in current with respect to angle by using NaaV meter 
To Study the Nature of Geopathic Stress Caused by Ground Water using NaaV Meter and Proton Magnetometer

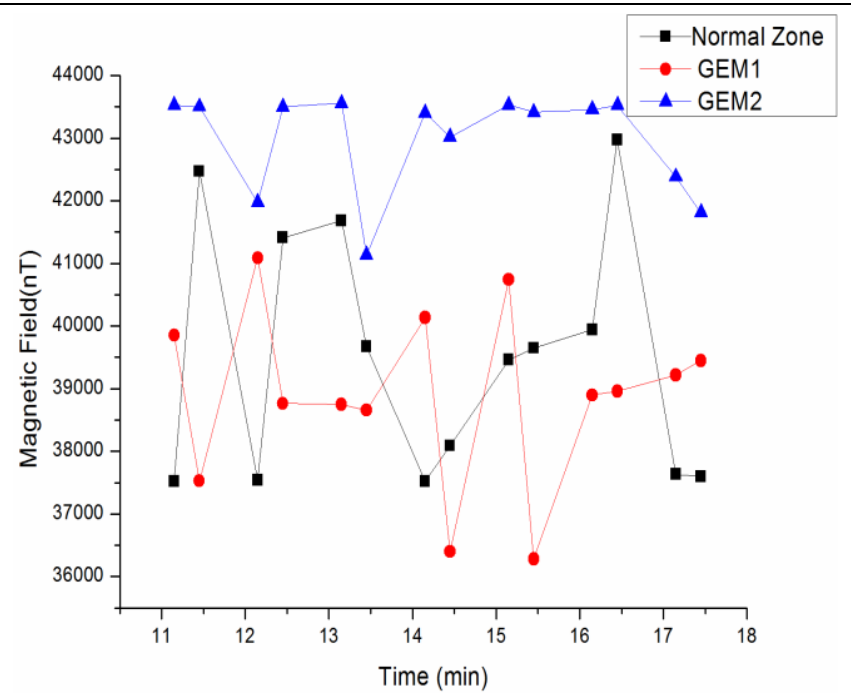

Fig 3. Graph for variation in Magnetic field with respect to time for two different GS and normal zone by using Proton magnetometer

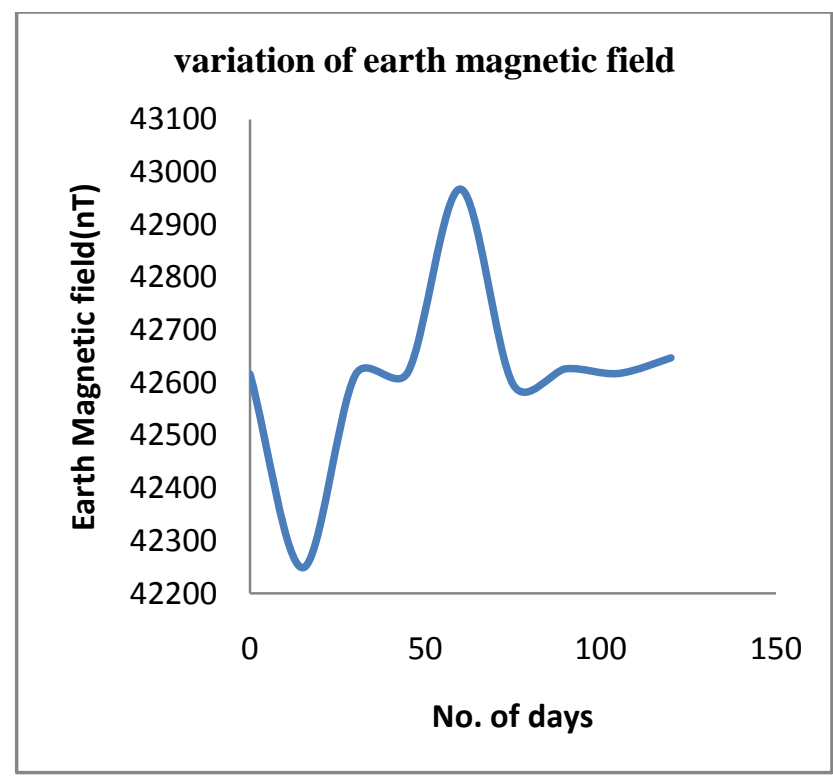

Fig 4. Graph for variation in Magnetic field with respect to days for GS and normal zone by using Proton magnetometer

\section{RESULT AND DISCUSSION}

The assembly of laser source and detector together is rotated with respect to upcoming geopathic stress. The current in micro-ammeter is measured for different angles. Initially for 00 i.e. when geopathic stress is perpendicular to experimental assembly the current is observed to be minimum (figure 2).Change in angle by 100 , increases the current value. It reaches maximum and further decreases as the angle changes, till a minimum is observed. Further increase in angle increases the current values. It indicates that the intensity of horizontally moving laser beam changes due to the obstacle of vertically moving geopathic stress.

For one complete 3600 rotation of experimental assembly, two peaks are observed.

Daily earth magnetic field variations for the 4 months period (January to April) are collected using Proton Magneto Meter (PMM). Daily geomagnetic field observations were taken in the afternoon during 1400-1730 hrs to study the effect of connective storms on the earth magneticfield variations.

\section{CONCLUSION}

The study and analysis of geopathic stress using NaaV meter indicates that GS are in the form of Electric field and Proton Magnetometer gives indication about Magnetic field. This study shows that Geopathic Stress is combination of Electric and Magnetic field vectors. 
To Study the Nature of Geopathic Stress Caused by Ground Water using NaaV Meter and Proton Magnetometer

\section{REFERENCES}

[1] Geopathic stress: a study to understand its nature using Light Interference Technique N. P. Dharmadhikari Current Science Vol. 98, No. 5 (10 March 2010), pp. 695-697

[2] Telford, W.M., Geldart, L.P., Applied Geophysics, Cambridge University Press, NY, 859, 1976.

[3] Von Pohl G F., Earth currents: Causative factors of cancer and other diseases, Frech-Verlag, Stuttgart, 1993.

[4] Derek J Croome., The Effect of Geopathic Stress on Building Occupants, Renewable Energy, 1994, 993 996.

\section{AUTHOR'S BIOGRAPHY}

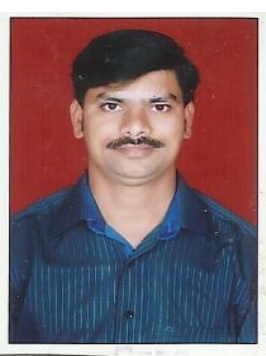

\section{Aishwarya Bhimraj Gawand,}

M.Sc., M.Phil.(Mathematics), MBA (Finance)

Working as Assistant Professor (Mathematics) in JSPM's Jayawantrao Sawant College of Engineering, Pune

Teaching Experience: 15 years

Citation: A. B. Gawand, S. B. Gaikwad, "To Study the Nature of Geopathic Stress Caused by Ground Water using NaaV Meter and Proton Magnetometer ", International Journal of Scientific and Innovative Mathematical Research, vol. 6, no. 3, p. 25-28, 2018., http://dx.doi.org/10.20431/2347-3142.0603003

Copyright: (C) 2018 Authors. This is an open-access article distributed under the terms of the Creative Commons Attribution License, which permits unrestricted use, distribution, and reproduction in any medium, provided the original author and source are credited. 